Thorax, 1981, 36, 241-244

\title{
Editorial
}

\section{Asbestos and public health}

The highly complex health effects of asbestos have been the subject of many symposia and publications over the last two decades. The Health and Safety Commission's Advisory Committee on Asbestos produced its final report ${ }^{1}$ late in 1979; in a second volume (of commissioned papers), there is an excellent review by Acheson and Gardner of the Ill-Effects of Asbestos on Health. ${ }^{2}$ More recently, McDonald's team has published the latest report of mortality in a very large cohort of Quebec miners and millers, ${ }^{3}$ and the proceedings of a symposium held at the (WHO) International Agency for Research on Cancer, in Lyon, in September 1979, have now appeared. ${ }^{4}$ At the September 1980 British Occupational Hygiene Society's Symposium on Inhaled Particles, all but one of the asbestos papers fitted and helped to fill out the pattern. The findings from the last were completely out of line with anything that has gone before; so much so that reasonable scientists must await careful evaluation before allowing this paper ${ }^{5}$ to influence judgement based on scores of well-authenticated reports. With this single exception, matters have become sufficiently clear that reasonable synthesis seems possible. This editorial draws freely on many sources but, to keep within reasonable limits, it concentrates largely on mortality in relation to asbestos exposure, with especial reference to death from lung cancer. Morbidity is given less weight because of the greater difficulties of diagnosis and attribution, particularly bearing in mind the interactions with smoking. In view of the recent editorial, ${ }^{6}$ mesotheliomas are reviewed only cursorily.

The bulk of the Western World's asbestos is "chrysotile," a magnesium silicate mined mainly in Quebec; the remainder consists of the so-called "amphiboles," ferrous and ferric silicates-almost entirely crocidolite and amosite-both now produced only in South Africa. Russia produces almost as much chrysotile as the rest of the world, mainly for "home" consumption, but no amphibole.

It is now thought that the dimensions of retained fibres in the lung are more important in carcinogenesis than their chemical composition, while the processes of inhalation, elimination, and retention also seem to depend on physical characteristics. It is

Address for reprint requests: Professor D Liddell, Department of Epidemiology and Health, McGill University, 3775 University Street, Montreal, Quebec, Canada H3A 2 B4. possible that chrysotile may not penetrate deeply and that those fibres which are initially retained become susceptible to the system of natural elimination including dissolution. Amphiboles, on the other hand, may penetrate quite deeply, and their relative indestructibility seems to lead to retention more or less indefinitely. Whatever the mechanisms, it seems that, on average and where exposures are similar, considerably less chrysotile than amphibole is found in the lung post mortem. ${ }^{78}$ If these beliefs are wellfounded, it is clear that, compared with chrysotile, the amphiboles have substantially greater potential for causing ill effects.

Also important is that, with all asbestos-related disease, there is a delay, usually of several decades, between first exposure to respirable fibres and the onset of symptoms. Thus, today's cases are not attributable to present conditions, but to those of 40 or more years ago. Meanwhile new cases can arise several decades after cessation of exposure. It is also clear that it could take up to half a century before there would be any serious possibility of discovering whether control had been satisfactory and perhaps a like period before the appearance of a new hazard.

In no study in man is it possible to measure the dose - that is, the amount of dust reaching or better, retained in, the target organ. At best, measurements can be made of the fibre concentrations in the air close to that inspired by individual workers. Personal samplers are now in use, but in the past only assessments in the general area of the work place were possible, and even these have been available in very few studies. With such measurements, linked to work histories, it is possible to assess roughly the exposure experienced by each worker in certain periods, and this may be a reasonably satisfactory index of dose. Without such measurements, the only available surrogate is duration of exposure; this has been used in most studies, but is obviously less than satisfactory and, indeed, of dubious validity.

If only for the difficulties just mentioned, there can be no ideal epidemiological study. The best have been in occupational settings and that of Quebec chrysotile production workers ${ }^{3}$ has many advantages over most. A large birth cohort of 10939 males and $\mathbf{4 4 0}$ females who worked at least a month in the industry, some as early as 1904, was followed to the end of 1975 ; only $2 \%$ of those known to be alive in 1936 were untraced 
and there had been nearly 4500 deaths. Estimates of respirable dust concentrations, job by job, were obtained to cover the relevant periods of exposure, and smoking histories were obtained for almost all men alive in 1950 . The data have been analysed by different methods, ${ }^{9}$ and the results have been consistent. ${ }^{10}$ The inclusion of those with very short employment led to a very wide range of accumulated dust exposure-the summation, job by job, of dust concentration multiplied by years in the job. This overcame some of the problems of selection and survival that arise when a study group is defined in terms of long employment, or employment at a particular time, as has been usual in other studies.

The advantage of having such a wide range of exposures is that it allows study of the shape of the exposure-response relationship; in Quebec for lung cancer it was effectively linear. ${ }^{3} 911$ Results from other studies have tended to support such a relationship ${ }^{12}$ or one that is possibly "sub-linear"-that is, steeper for short periods of exposure and more shallow for longer periods. ${ }^{13}$ Either way, there seems no evidence for a threshold or "safe" dose. The implications of this are important.

It is difficult to make quantitative comparisons between the health effects of the different types of asbestos fibre. For many purposes, mixtures of amphibole and chrysotile have been found satisfactory from a commercial point of view, and there are very few large groups of workers (other than miners and millers) who have been exposed to a single fibre type. Even were single-fibre studies possible, differences in selection and management policies, problems over reference populations, and the almost certain lack of information on dust concentrations, all militate against reliability of comparison. In mixed-fibre studies, where groups of workers have been distinguished by exposure to a single fibre, the above factors should be standardised. However, the classification by fibre type may have been imperfect (or there may have been contamination), and numbers have tended to be rather small.

The findings from most studies to date appear to support the hypothesis of a "fibre gradient", such that crocidolite has much the most severe health effects, and chrysotile the least, with amosite somewhere in between. This is compatible with the beliefs expressed in the third paragraph of this editorial, and the gradient seems to exist with all health hazards. For mesothelioma, the gradient is undoubted, and is almost certainly steeper for this outcome than for any other. ${ }^{14} 15$

As to lung cancer, the gradient still exists although it is probably not quite so steep. Chrysotile production has yielded a comparatively mild excess. ${ }^{3} 16$ Only a handful of small studies in chrysotile processing have been reported, and their findings are all difficult to interpret; they are not incompatible with risks higher than in mining and milling, but much less than with the amphiboles (except in reference 5). The risk of lung cancer in pure crocidolite exposure was much higher in Nottingham, ${ }^{17}$ Eastern Canada, ${ }^{18}$ and Western Australia, ${ }^{19}$ and some of the highest risks were in amphibole-rich mixtures. ${ }^{20} 21$

Gastrointestinal cancers appear to be asbestosassociated only in certain circumstances, so that some other aetiological factor may also be involved. ${ }^{14}$ Cancer of the larynx was clearly unrelated to asbestos exposure in Quebec ${ }^{3}$ and in London, ${ }^{22}$ but has been associated with asbestos, probably amphibole, in a few other studies. ${ }^{2}$ Fortunately, the tumour is rare and even if there is an enhanced risk from asbestos exposure, the absolute effect on total mortality is undoubtedly small. Diagnosis of asbestosis in life is so difficult (because even the radiological signs are not specific and some history of asbestos exposure is required) that reliable comparisons between fibre type can only be made where the diagnoses have been made by the same team. Diagnosis of asbestosis at death is inevitably related to awareness and to compensation procedures. However, what evidence there is suggests the same gradient, if perhaps even less steep, by fibre type. ${ }^{2}$

Cigarette smoking is an important factor in lung cancer and cancer of the larynx, but does not seem to affect the risk of mesothelioma or of gastrointestinal cancer, and perhaps not of asbestosis. In the latest Quebec data on lung cancer, ${ }^{3}$ the slope of the asbestos exposure-response line appeared to depend on smoking habits, being steeper for non-smokers than for definite smokers; other data seem to fit the multiplicative model better. ${ }^{23}{ }^{24}$ However, from the Quebec data it is clear, whatever the model, that today's control limits for occupational exposure to chrysotile are equivalent in carcinogenic potency to very light smoking - that is, only three or four cigarettes smoked each week.

Bearing in mind the lag period, it is important to consider findings in men with low exposures to chrysotile. In analysis of the Quebec data on lung cancer up to the end of 1973 , it was reported ${ }^{9}$ that no excess was detectable (at anything approaching a conventional level of statistical significance) where $\stackrel{\Phi}{\Phi}$ exposure was less than a certain amount, based on the integration over time of a concentration of respirable asbestos dust. This is equivalent to saying that (on the linear hypothesis and with a conservative fibre/dust conversion ratio) in a 50-year working lifetime, in $\mathrm{O}$ concentrations below about 20 respirable fibres per millilitre of air (ie $20 \mathrm{f} / \mathrm{ml}$ ), no excess could have been 8 detected with any confidence. The proposed control limit $^{1}$ for occupational exposure to asbestos is of a 
concentration of $1 \mathrm{f} / \mathrm{ml}$, or one-twentieth that indicated in parentheses above. At Rochdale (where the fibre was mainly chrysotile but where there was probably significant use of crocidolite even into the 1960s), no relationship was found-in those who had entered the industry after 1951-between lung cancer and exposure up to the equivalent of $8 \mathrm{f} / \mathrm{ml}$ for 50 years. ${ }^{25}$

Other low exposures have occurred in nonoccupational settings ${ }^{2}$; it is difficult to see how concentrations can have been severe enough for long enough for them to have been a serious hazard in the past, except where there was domestic contact with asbestos workers.

Over the next decade or longer, more cases of asbestos-related disease will undoubtedly appearbut they will be the result of working conditions 30-40 years before their appearance. However, conditions have generally been improving for at least two decades, and it is possible that we are already over the worst of the pathological effects, despite some questionable forecasts informally, but widely, circulated in the USA. ${ }^{26}$ Should any cases arise from today's levels of exposure they will not be seen until well into the twenty-first century.

The latest UK government regulations limiting occupational exposure to chrysotile to $1 \mathrm{f} / \mathrm{ml}$ from 1981 do not, of course, guarantee absolute safety. Even if it were assumed that there had been no crocidolite at the Rochdale factory, and putting a very gloomy interpretation on the findings there, 50 years' continuous exposure to the upper limit allowed by the regulations would lead to $1.25 \%$ excess mortality from lung cancer, or about $0.125 \%$ overall excess. ${ }^{2}$ Crocidolite is, of course, subject to much more stringent regulations-no more imports and especial care in any necessary processing or handling. As amosite is an amphibole, and as evidence against it is accumulating, it would seem sensible to treat it on the same lines as crocidolite. One reason is that chrystotile can, perhaps with some ingenuity, often be used instead, although there will remain specific problems such as the production of large-diameter pressure pipes.

Non-occupational exposures to asbestos may continue because of demolition or damage to certain building materials, particularly those used for insulation where the materials often contained amphiboles. There is no doubt that any exposure to respirable asbestos is to be avoided wherever possible, and strict precautionary measures during repair or replacement are clearly indicated. Nevertheless, great care must be exercised that the hazards during such operations are no worse than those arising "naturally"- that is, from leaving the asbestos in situ. It is also important to note that the peak figure identified in a survey ${ }^{27}$ of buildings containing asbestos materials in the UK was only $0.08 \mathrm{f} / \mathrm{ml}$ (one-twelfth of the proposed control limit for occupational exposure); however, it is agreed that more information is required "about asbestos levels in new and old buildings in relation to type and usage of asbestos-containing materials, particularly insulation materials." 2 No ill effects have yet been demonstrated of asbestos in drinking water, in food and beverages or in the general atmosphere. Indeed, the pollution of the air around Thetford Mines, by far the dustier of the two mining areas in Quebec, was for many decades quite severe, but there was no evidence that excess asbestos-related mortality or morbidity in the general population could not be attributed to occupational exposure.

A final point must be made about substitutes for asbestos. Some adequate substitutes exist which do not resemble asbestos; where they do, it should be borne in mind that the better a substitute mimics the physical and chemical properties of asbestos the closer the ill effects on health are likely to be. Indeed, there is animal evidence ${ }^{28}$ that glass fibre of the same dimensions as crocidolite has biological effects at least as serious as those of the amphibole. It must also be emphasised that at least 30 years' exposure of a large group of workers would be required to "test" any substitute, and even then it would not be possible to demonstrate that it was "safe."

\section{DOUGLAS LIDDELL \\ Department of Epidemiology and Health McGill University, Montreal, Quebec, Canada}

\section{References}

1 Health and Safety Commission. Asbestos Volume 1: final report of the advisory committee. London: HMSO, 1979.

2 Acheson ED, Gardner MJ. The ill-effects of asbestos on health. In: Health and Safety Commission. Asbestos Volume 2: papers prepared for the advisory committee. London: HMSO 1979: 7-83.

3 McDonald JC, Liddell FDK, Gibbs GW, Eyssen GE, McDonald AD. Dust exposure and mortality in chrysotile mining, 1910-75. Br J Ind Med 1980; 37: 11-24

4 Wagner JC Ed. Biological Effects of Mineral Fibres: Proceedings of a Symposium organised by IARC, the French National Institute of Health and Medical Research and the Medical Research Council, Penarth, $U K$, held at the International Agency for Research on Cancer, Lyon, France, 25-27 September 1979. IARC Scientific Publication no 30. Lyon: IARC, 1980.

5 Dement JM, Harris RL Jr, Symons MJ, Shy C. Estimates of dose-response for respiratory cancer among chrysotile asbestos textile workers. In : 
Walton WH, Critchlow A eds. Inhaled Particles $V$. Oxford: Pergamon Press, 1981.

6 Elmes PC. Mesotheliomas, minerals, and man-made mineral fibres. Thorax 1980; 35: 561-3.

7 Gibbs GW. Personal communication, 1980.

8 Rowlands N, Gibbs GW, McDonald AD. Asbestos fibres in the lungs of chrysotile miners and millers: a preliminary report. In: Walton WH, Critchlow A eds. Inhaled Particles V. Oxford: Pergamon Press, 1981.

9 Liddell FDK, McDonald JC, Thomas DC. Methods of cohort analysis: appraisal by application to asbestos mining. J R Stat Soc 1977; Series A 140: 469-91.

10 McDonald JC, Liddell FDK. Mortality in Canadian miners and millers exposed to chrysotile. Ann NY Acad Sci 1979; 330: 1-10.

11 Berry G. Dose-response in case-control studies. $J$ Epidemiol Commun Med 1980; 34:217-22.

12 Henderson VL, Enterline PE. Asbestos exposure: factors associated with excess cancer and respiratory disease mortality. Ann NY Acad Sci 1979; 330: 117-26.

13 Seidman H, Lilis R, Selikoff IJ. Short-term asbestos exposure and delayed cancer risk. In: Niebergs HE ed. Proceedings of Third International Symposium on Detection and Prevention of Cancer, Part I, Vol 7. New York: Marcel Dekker, 1979: 943-60.

14 McDonald JC. Asbestos-related disease: an epidemiological review. In: Wagner JC ed. Biological Effects of Mineral Fibres: Proceedings of a Symposium organised by IARC, the French National Institute of Health and Medical Research and the Medical Research Council, Penarth, UK, held at the International Agency for Research on Cancer, Lyon, France, 25-27 September 1979, IARC Scientific Publication no 30. Lyon: IARC, 1980; 2:587-601.

15 McDonald AD, McDonald JC, Pooley FD. Mineral fibre content of mesothelial tumours in North America. In: Walton WH, Critchlow A eds. Inhaled Particles V. Oxford: Pergamon Press, 1981.

16 Rubino GF, Piolatto G, Newhouse ML, Scansetti G, Aresini GA Murray R. Mortality of chrysotile asbestos workers at the Balangero Mine, Northern Italy. Br J Indl Med 1979; 36: 187-94.

17 Jones JSP, Smith PG, Pooley FD et al. The consequences of exposure to asbestos dust in a wartime gas-mask factory. In: Wagner JC ed. Biological Effects of Mineral Fibres: Proceedings of a Symposium organised by IARC, the French National Institute of Health and Medical Research and the Medical Research Council, Penarth, UK, held at the International Agency for Research on Cancer, Lyon, France, 25-27September 1979. IARC Scientific Publication no 30. Lyon: IARC, 1980; 2:637-53.

18 McDonald AD, McDonald JC. Mesothelioma after crocidolite exposure during gas mask manufacture. Environ Res 1978; 17: 340-6.

19 Hobbs MST, Woodward SD, Murphy B, Musk AW, Elder JE. The incidence of pneumonoconiosis, mesothelioma and other respiratory cancer in men engaged in mining and milling crocidolite in Western Australia. In: Wagner JC ed. Biological Effects 흘 of Mineral Fibres: Proceedings of a Symposium क organised by IARC, the French National Institute $\overparen{\otimes}$ of Health and Medical Research and the Medical Research Council, Penarth, UK, held at the Inter- os national Agency for Research on Cancer, Lyon, $\overrightarrow{0}$ France, 25-27 September 1979. IARC Scientific Publication no 30. Lyon: IARC, 1980; 2:615-25.

20 Newhouse ML. Asbestos in the workplace and the community. Ann Occup Hyg 1973; 16: 97-107.

21 Selikoff IJ, Hammond EC. Multiple risk factors in environmental cancer. In: Fraumeni JF ed. Persons at high risk of cancer: an approach to cancer aetiology i and control. London: Academic Press, 1975: 467.

22 Newhouse ML, Gregory MM, Shannon H. 을 Etiology of carcinoma of the larynx. In: Wagner JC ed. Biological Effects of Mineral Fibres: $\rightarrow$ Proceedings of a Symposium organised by IARC, the French National Institute of Health and Medical Research and the Medical Research Council, Penarth, $\infty$ UK, held at the International Agency for Research on.Cancer, Lyon, France, 25-27 September 1979. IARC ס Scientific Publication no 30. Lyon: IARC, 1980; 웅 2:687-95.

23 Saracci R. Asbestos and lung cancer: an analysis of the epidemiological evidence on the asbestos- $\frac{\odot}{\varnothing}$ smoking interaction. Int J Cancer 1977; 20: 323-31.

24 Hammond EC, Selikoff IJ, Seidmann H. Asbestos $\overrightarrow{\overrightarrow{0}}$ exposure, cigarette smoking and death rates. Ann $N Y 3$ Acad Sci 1979; 330: 473-90.

25 Peto J. Lung cancer mortality in relation to measured dust levels in an asbestos textile factory. In: Wagner JC ed. Biological Effects of Mineral Fibres: Pro- 으 ceedings of a Symposium organised by IARC, the 叉्ञ French National Institute of Health and Medical Research and the Medical Research Council, Penarth, $\underline{3}$ UK, held at the International Agency for Research on Cancer, Lyon, France, 25-27 September 1979. IARC 욱 Scientific Publication no 30. Lyon: IARC, 1980; 2:829-36.

26 Peto R. Distorting the epidemiology of cancer: the $D$ need for a more balanced view. Nature 1980; 284: 297-300.

27 Byron JC, Hodgson AA, Holmes S. A dust survey O carried out in buildings incorporating asbestos-based $N$ materials. Ann Occup Hyg 1969; 12: 141-5.

28 Miller $\mathrm{K}$. The in vivo effects of glass fibres on alveolar macrophage membrane characteristics. In: Wagner JC ed. Biological Effects of Mineral Fibres: Pro- $\bullet$ ceedings of a Symposium organised by IARC, the $\mathbb{\Phi}$ French National Institute of Health and Medical $?$ Research and the Medical Research Council, Penarth, $\frac{T}{-}$ UK, held at the International Agency for Research on

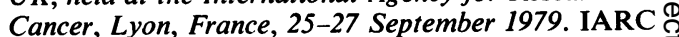
Scientific Publication no 30. Lyon: IARC, 1980; $\mathbb{8}$ 1:459-65. 